\title{
HTLV-1 and HTLV-2: highly similar viruses with distinct oncogenic properties
}

\author{
Vincenzo Ciminale ${ }^{1}$, Francesca Rende ${ }^{1}$, Umberto Bertazzoni ${ }^{2}$ and Maria G. Romanelli ${ }^{2}$ * \\ ${ }^{1}$ Department of Surgery, Oncology and Gastroenterology, University of Padua, Padua, Italy \\ ${ }^{2}$ Department of Life and Reproduction Sciences, University of Verona, Verona, Italy
}

\author{
Edited by: \\ Hirofumi Akari, Kyoto University, \\ Japan \\ Reviewed by: \\ Hidekatsu Iha, Oita University, Japan \\ Fatah Kashanchi, George Mason \\ University, USA \\ *Correspondence: \\ Maria G. Romanelli, Department of \\ Life and Reproduction Sciences, \\ University of Verona, Strada le Grazie \\ 8, Verona 37134, Italy \\ e-mail: mariagrazia.romanelli@univr.it
}

HTLV-1 and HTLV-2 share broad similarities in their overall genetic organization and expression pattern, but they differ substantially in their pathogenic properties. This review outlines distinctive features of HTLV-1 and HTLV-2 that might provide clues to explain their distinct clinical outcomes. Differences in the kinetics of viral mRNA expression, functional properties of the regulatory and accessory proteins, and interactions with cellular factors and signal transduction pathways are discussed.

Keywords: HTLV, Tax, Rex, HBZ, APH2, clonality

\section{INTRODUCTION}

Four types of HTLV have been described so far, the most prevalent types being HTLV-1 and HTLV-2 (Gessain et al., 2013).

HTLV-1 and HTLV-2 show considerable homology in terms of genome structure, replication pattern, and properties of the structural, regulatory, and accessory proteins. Their transmission follows the same route, by transfer of infected lymphocytes by perinatal transmission and breastfeeding and through blood transfusion, sexual contact, and use of intravenous drugs (Pique and Jones, 2012). Both viruses utilize the GLUT-1 and NRP1 cellular receptors for their entry, although HTLV-1, but not HTLV-2, is dependent on heparan sulfate proteoglycans (Jones et al., 2006). Cell-to-cell transmission is essential for virus replication and occurs through the formation of a virological synapse (Nejmeddine et al., 2005).

Despite these important analogies, HTLV-1 and HTLV-2 are strikingly different in terms of clinical impact, as only HTLV-1 is conclusively associated with neoplasia, namely adult T-cell leukemia/lymphoma (ATLL), which develops in up to $5 \%$ of infected individuals. A similar percentage of HTLV-1-infected persons develop a neurological disease termed HTLV-associated myeolopathy/tropical spastic paraparesis (HAM/TSP; Gessain and Mahieux, 2012). In contrast, HTLV-2, though persistently associated with elevated lymphocyte and platelet counts (Bartman etal., 2008) and with an increase in overall cancer mortality (Biswas et al., 2010), does not cause hematologic disorders and is only sporadically associated with myelopathy (Araujo and Hall, 2004).

The two viruses also differ in their geographical distribution. HTLV-1 is endemic in Japan, sub-Saharan Africa, South America, and the Caribbean (Gessain and Cassar, 2012), whereas HTLV-2 is prevalent among the indigenous populations in Africa and the Indian-American tribes in Central and South America as well as among drug users in Europe and North America (Zella et al., 1990; Roucoux and Murphy, 2004). Although their receptor usage allows HTLV-1 and HTLV-2 to be quite promiscuous for different cell types in vitro, they exhibit distinct cellular tropisms in vivo: HTLV-1 is mainly found in CD4+ T lymphocytes, whereas CD8+ T cells are the preferred target for HTLV-2 (Ijichi et al., 1992).

The following sections highlight differences in the biology of HTLV-1 and HTLV-2 that might provide clues to their distinct clinical outcomes. Emphasis is placed on the comparison of the regulatory proteins, kinetics of mRNA expression, clonal distribution patterns, and interaction with cellular factors and signal transduction pathways.

\section{THE COMPARATIVE ANATOMY OF THE HTLV-1 AND HTLV-2 GENOMES}

In their pioneering studies, Seiki et al. (1983) noted the presence of a region in the HTLV-1 genome between the env open reading frame (ORF) and the $3^{\prime}$ LTR that was not present in the previously described oncogenic retroviruses. This region, termed the "X region," is also present in HTLV-2 and codes for the regulatory and accessory proteins in partially overlapping ORFs named $\mathrm{x}-\mathrm{I}$ through $\mathrm{x}-\mathrm{V}$. Expression of the complex arrangement of ORFs in such a compact genome is accomplished by a combination of ribosomal frameshifting, alternative splicing, and polycistronic translation (Ciminale et al., 1992, 1995; Koralnik et al., 1992) as well as production of negative-strand transcripts that code for the HBZ (HTLV-1) and APH-2 (HTLV-2) proteins.

Like other retroviruses, the HTLVs produce an unspliced mRNA which codes for the Gag-Pol-Pro precursor protein and also serves as the viral genome and a singly spliced mRNA that codes for the Env surface glycoproteins. Peculiar to the HTLVs is the expression of the Tax and Rex regulatory proteins that play critical roles in driving expression from the $5^{\prime}$ LTR promoter (Tax) and in enhancing the expression of partially spliced plus-strand mRNAs (Rex). The Tax and Rex ORFs (x-IV and x-III, respectively) are expressed from the same doubly spliced mRNA. In HTLV-1, 
all the other $\mathrm{X}$ region proteins are coded by individual singly or doubly spliced transcripts, while some HTLV-2 transcripts express more than one ORF.

Recent studies of the temporal sequence of HTLV-1 gene expression in peripheral blood mononuclear cells (PBMCs) isolated from infected patients (Corradin et al., 2011; Rende et al., 2011) revealed a "two-phase" kinetics with tax/rex mRNA expression preceding that of other viral transcripts. A similar analysis of HTLV-2 mRNA expression indicated a comparable pattern, although the relative abundance of some transcripts showed some intriguing differences among the two viruses (Bender et al., 2012; Cavallari et al., 2013).

The major differences between HTLV-1 and HTLV-2 gene products are summarized in Table $\mathbf{1}$ and commented in the following sections.

\section{Tax PROTEINS AND THEIR INTERACTIONS WITH CELLULAR PATHWAYS}

The principal role of Tax during viral replication is to activate transcription of the LTR promoter through a process that involves the recruitment of CREB/ATF complexes on binding sites in the U3 region. Tax-1 and Tax-2 share this mechanism and are able to cross-activate each others' LTRs (Semmes et al., 1996).

Experiments performed in the early 1990s established a key role for Tax as the main viral oncoprotein necessary for the initial steps of T-cell transformation by HTLV-1 (Tanaka et al., 1990). Transgenic mouse models have consistently demonstrated that Tax expression causes tumors, including lymphoma and leukemia (Ruddle et al., 1993; Hasegawa et al., 2006). Recent comparative studies on the transforming activities of HTLV-1 Tax (Tax-1) and HTLV-2 Tax (Tax-2) demonstrated that, in the absence of other viral proteins, both Tax- 1 and Tax- 2 immortalize human primary CD $4+\mathrm{T}$ cells, but only Tax -2 is able to immortalize CD8+ T cells (Imai et al., 2013). Furthermore, Tax-2 immortalizes human primary CD4 $+\mathrm{T}$ cells more efficiently than Tax-1 (Imai et al., 2013). Although additional viral products have been demonstrated to be relevant for immortalization, the interactions between Tax and host proteins are still considered to be essential for the transformation process. Several studies of the oncogenic properties of Tax-1 highlighted its effects on DNA repair, cell cycle progression, cell death, and p53 function (reviewed by Cheng et al., 2012).

In addition to CREB/ATF proteins, Tax-1 interacts with many other host factors that influence cell proliferation and transformation, including components of the PI3K, AKT, MAPK, TGF $\beta$, SRF, and NF- $\kappa$ B pathways (Romanelli et al., 2013). Tax-2 has been analyzed mainly for its effects on the NF- $\kappa \mathrm{B}$ pathway, and was shown to activate the canonical pathway, but, unlike Tax-1, does not activate the noncanonical pathway (Shoji et al., 2009), suggesting that activation of this latter pathway might be a key element in HTLV-1-driven transformation in vivo. Although overall highly homologous, Tax-1 and Tax-2 present some distinct structural features. Tax-1 contains a PDZ binding motif (PBM) and leucine zipper domains that are absent in Tax-2. The C-terminal PBM domain is relevant for interaction of Tax-1 with host factors that regulate cell cycle progression and proliferation, such as the human homologue of the Drosophila melanogaster disk large tumor suppressor protein (hDLG; Suzuki et al., 1999). The leucine zipper regions present in the central region of Tax-1 are responsible for activation of the non-canonical NF- $\kappa \mathrm{B}$ pathway (Higuchi and Fujii, 2009). The nuclear localization and nuclear export signals of Tax-1 and Tax-2 present significant differences which could explain the predominant nuclear localization of Tax-1 compared to Tax-2 (Turci et al., 2006, 2009; Avesani et al., 2010).

An additional difference between Tax- 1 and Tax- 2 that may play a role in NF- $\kappa \mathrm{B}$ activation is the absence of interactions between Tax-2 and TNF receptor-associated factor TRAF6, an E3 ubiquitin ligase that is involved in ubiquitination of effectors of the NF-кB pathway (Journo et al., 2013). Both Tax-1 and Tax-2 are ubiquitinated and SUMOylated, but they differ in the pattern of modification (Zane and Jeang, 2012). The role of ubiquitination, sumoylation, and acetylation of Tax in NF- $\kappa$ B activation and cellular transformation is still an open field of research (Turci et al., 2012; Xiao, 2012; Journo et al., 2013; Lodewick et al., 2013).

Activation of NF- $\kappa$ B by Tax is also connected to the deregulation of autophagy, an additional pathway that is altered in oncogenic signaling. Both Tax-1 and Tax-2 induce autophagosome accumulation, but their interactions with the components of the process differ. In fact, Tax-1 (but not Tax-2) directs the IKK complex to lipid rafts associated with autophagic molecules such as Beclin 1 and Bif-1 (Huang et al., 2009; Ren et al., 2013).

\section{POST-TRANSCRIPTIONAL REGULATION BY Rex}

HTLV-1 Rex (Rex-1) and HTLV-2 Rex (Rex-2) share 60\% homology at the amino acid level. Rex- 1 and Rex- 2 are phosphorylated proteins that actively shuttle between the nucleus and the cytoplasm (Palmeri and Malim, 1996; Narayan etal., 2003) and accumulate in the nucleus and nucleoli (Nosaka et al., 1989; Ciminale et al., 1995, 1997; Nosaka et al., 1995; Narayan et al., 2003), a property that is intimately linked to their ability to enhance the nuclear export of incompletely spliced viral mRNAs.

Rex-1 and Rex-2 share a similar domain structure which includes: (i) a nuclear localization signal (NLS; Siomi et al., 1988; Nosaka et al., 1989), which mediates binding to the RXRE (Grassmann et al., 1991) located at the $3^{\prime}$ end of all HTLV-1 transcripts and at the $5^{\prime}$ end of the unspliced HTLV-2 mRNA (Ohta et al., 1988; Black et al., 1991); (ii) multimerization domains; and (iii) a leucine-rich sequence located near the middle of the protein (Rex-1 aa 79-99; Rex-2 aa 81-94), which functions as an activation domain (AD; Weichselbraun et al., 1992) and contains the nuclear export signal (NES; Kim et al., 1996; Palmeri and Malim, 1996) that interacts with CRM1/exportin, which mediates the nuclear export of the Rex-viral mRNA complex (Bogerd et al., 1995; Kim et al., 1996; Palmeri and Malim, 1996). In addition a C-terminal domain unique to Rex-2 is a target for serine phosphorylation and may also contribute to efficient nucleocytoplasmic shuttling (Narayan et al., 2003). Although Rex is not required for cellular immortalization in vitro, it is necessary for infectivity and viral persistence in vivo (Ye et al., 2003), as it is required for the expression of the virion-associated structural proteins.

The dependence of HTLV mRNAs on Rex function is controlled by positively and negatively acting RNA sequences present 
Table 1 | Structural and functional differences between HTLV-1 and HTLV-2 gene products.

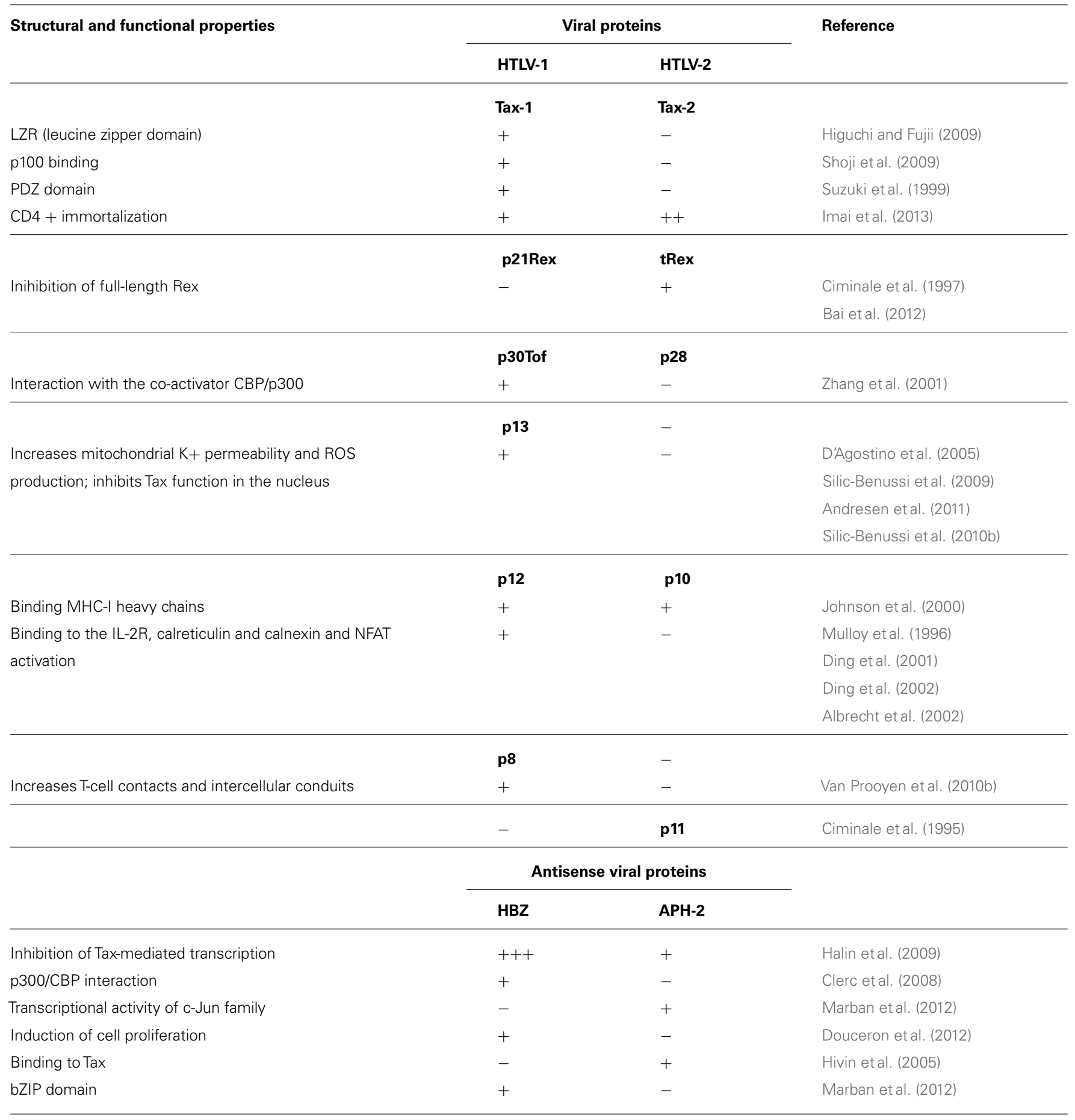

on the primary transcript. Two major types of such RNA cis-acting elements have been described: (i) the Rex responsive element (RXRE) which, besides binding Rex, acts as an inhibitory sequence in the absence of Rex, and (ii) cis-acting repressive sequences (CRS) that determine poor stability and/or inefficient nucleocytoplasmic export. HTLV-1 contains a CRS which maps at the $5^{\prime}$ end of the unspliced mRNA but is spliced out of the other transcripts (Seiki et al., 1990; King et al., 1998). An additional CRS overlaps the RXRE and acts synergistically with the $5^{\prime}$ CRS. In contrast to the $5^{\prime}$-CRS, this $3^{\prime}$-CRS/RXRE is present at the $3^{\prime}$ end of all viral transcripts. Both the $5^{\prime}$ - and $3^{\prime}$-CRSs were shown to act mainly as nuclear retention sequences. The 5'-CRS does not bind Rex-1 (Ballaun et al., 1991; Bogerd et al., 1991; Unge et al., 1991), and its inhibitory function is likely to 
be mediated by other viral and/or cellular RNA-binding proteins. Other cis-acting inhibitory elements (CIEs) were mapped within the gag-pol and env regions of HTLV-1 (Saiga et al., 1997). The inhibitory effect of these regions is counteracted by binding of Rex-1 to the RXRE, although it is not clear whether they function mainly at the level of RNA stability or nucleocytoplasmic export. A $5^{\prime}$-CRS acting as a nuclear retention sequence was also mapped in the R-U5 region of HTLV-2 (Black et al., 1991).

\section{THE ACCESSORY PROTEINS}

The "accessory" proteins were labeled as such because their ablation does not have apparent consequences on viral replication in vitro. However, studies performed in animal models indicate that some of these proteins are essential for efficient infectivity in vivo. Among the accessory proteins, p30Tof/p28, p12/p10, and p21Rex/tRex (in HTLV-1 and HTLV-2, respectively) are considered to be homologous based on their structure and functional properties, while $\mathrm{p} 13$ and $\mathrm{p} 8$ appear to be unique to HTLV-1, and p11 is peculiar to HTLV-2.

p21Rex and tRex are truncated forms of Rex-1 and Rex-2, respectively, which lack the $N$-terminal arginine-rich NLS and are therefore incapable of binding the RXRE. HTLV-2 tRex is detected as four main isoforms of $22,20,18$, and $17 \mathrm{kDa}$ which differ in the initiation codon usage and phosphorylation status (Ciminale et al., 1997). The tRex proteins were shown to inhibit Rex-2 function (Ciminale et al., 1997), an activity that might favor latent infection. Although one study indicated that p21rex acts as a repressor of full-length Rex (Heger et al., 1999), this finding was not supported by other studies (Ciminale et al., 1997; Bai et al., 2012).

HTLV-1 p30Tof and HTLV-2 p28 are important for viral propagation in animal models (Silverman et al., 2004; Yamamoto et al., 2008; Valeri et al., 2010). Both proteins sequester the tax/rex mRNA in the nucleus, an effect that may result in reduced viral expression and latency (Nicot et al., 2004; Younis et al., 2004). p30Tof was also shown to interact with the RNA-binding domain of Rex and thereby interfere with its binding to the RXRE (SinhaDatta et al., 2007; Bai et al., 2010) and to inhibit the expression of Toll-like receptor 4 (Datta et al., 2006), suggesting a role in the innate immune response. These two properties have not been reported for p28. By interacting with the co-activator $\mathrm{CBP} / \mathrm{p} 300$ (Zhang et al., 2000, 2001), p30Tof also affects Tax-mediated viral expression and transcription of cellular genes involved in T-cell activation and apoptosis (Michael et al., 2004; Taylor et al., 2009). Interestingly, p28 does not appear to affect CBP/p300-mediated transcription. Both p30Tof and p28 are targeted to the nucleus, but only p30Tof shows evident accumulation in the nucleoli (Ciminale et al., 1995; D'Agostino et al., 1997). Interestingly, HTLV-2 p28 and tRex are expressed at higher levels compared to their HTLV-1 counterparts $\mathrm{p} 30 /$ Tof and $\mathrm{p} 21$ Rex, suggesting a higher propensity of HTLV-2 for latency compared to HTLV-1 (Bender et al., 2012).

p13 corresponds to the C-terminal 87 amino acids of p30Tof (Koralnik etal., 1992), and it is localized mainly in the mitochondrial inner membrane (Ciminale et al., 1999; D’Agostino etal., 2002) and in part to the nucleus (Silic-Benussi etal., 2010b; Andresen etal., 2011). Using a rabbit animal model,
Hiraragi etal. (2006) showed that p13 is required for viral infectivity in vivo. p13 increases mitochondrial permeability to $\mathrm{K}^{+}$and activates the electron transport chain, resulting in increased mitochondrial reactive oxygen species (ROS) production (Silic-Benussi et al., 2009). While p13 has a mitogenic effect in normal resting $\mathrm{T}$ cells, which have low ROS levels, the protein induces death of transformed T-cells, which are characterized by a high ROS setpoint (Ciminale et al., 1999; D'Agostino et al., 2005; Hiraragi etal., 2005; Silic-Benussi et al., 2004, 2010a,b). So far no HTLV-2 homologue of HTLV-1 p13 has been identified.

HTLV-1 p12 and its HTLV-2 homologue p10 are coded by the $x$-I ORF. p12 localizes in the endoplasmic reticulum (ER) and in the Golgi apparatus, where it reduces the expression of the $\beta$ and $\gamma_{c}$ chains of the interleukin-2 receptor (IL-2R, Mulloy et al., 1996) and of MHC-I, thus hindering lysis of HTLV-1-infected cells by CTL (Johnson et al., 2001). p12 also activates STAT-5, which provides a mitogenic signal to T cells (Nicot et al., 2001) and interacts with calreticulin and calnexin (Ding et al., 2001), resulting in incresased $\mathrm{Ca}^{2+}$ release from the ER (Ding et al., 2002) and activation of NF-AT, a mitogenic pathway in T-cells (Albrecht et al., 2002; Kim et al., 2003). Within the ER, p12 is cleaved into an $8-\mathrm{kDa}$ protein (p8) which trafficks to the immunological synapse and favours T-cell anergy. $\mathrm{p} 8$ also increases cell-to-cell viral transmission through the formation of intercellular conduits (Van Prooyen et al., 2010a,b). In analogy to p12, HTLV-2 p10 was shown to bind the MHC heavy chain; however, p10 does not bind the IL2R $\beta$ chain or the 16-kDa subunit of the vacuolar H+ ATPase (Johnson etal., 2000). No homologue of $\mathrm{p} 8$ has been described in HTLV-2.

A recent study from Valeri etal. (2010), showed that p12 is required for in vivo propagation in macaques but not in rabbits.

The $\mathrm{x}-\mathrm{V}$ ORF of HTLV-2 codes for p11 from a doubly spliced transcript that also codes for p10 (Ciminale et al., 1995). Aside from its ability to bind to MHC heavy chain (Johnson et al., 2000), nothing is known about the function of this protein. HTLV- 1 also possesses an $\mathrm{x}-\mathrm{V}$ ORF, but it does not appear to produce a $\mathrm{p} 11$ homologue. The function of p11 is still unclear.

\section{HBZ AND APH-2}

The structure and function of $\mathrm{HBZ}$ and $\mathrm{APH}-2$ were recently reviewed (Barbeau et al., 2013). HBZ is a nuclear transcriptional factor (Gaudray etal., 2002), able to interact with ATF/CREB proteins through its basic zipper (bZIP) domain causing the inhibition of its DNA-binding activity (Hivin et al., 2006); this effect also influences the ability of Tax-1 to activate HTLV-1 transcription (Halin et al., 2009). APH-2 is likewise able to inhibit Tax-2-mediated transcription but its repressive activity is weaker than that of HBZ (Halin et al., 2009). This difference may be ascribed to the presence in HBZ but not in APH-2, of a transcriptional activation domain within its $N$-terminal region that mediates its interaction with the KIX domain of p300/CBP, thus competing for its binding to Tax-1 (Clerc et al., 2008).

HBZ also deregulates several cellular pathways including c-Jun and JunD, FoxP3, NF- $\mathrm{BB}$, TGF- $\beta$ and Wnt (Barbeau et al., 2013). In addition, HBZ, may enhance its own expression by controlling 
the transcriptional activity of JunD (Gazon et al., 2012). Very little is known about the regulation of APH-2 expression in infected cells. However, unlike HBZ, APH-2 enhances the transcriptional activity of c-Jun family proteins (Marban et al., 2012).

The role of HBZ in T-cell transformation is supported by the finding that while Tax-1 expression is often repressed in ATL cells and appears to be dispensable for the late stages of leukemogenesis, HBZ is constitutively expressed in most ATL cases (Satou et al., 2006). Transgenic mice expressing HBZ in CD4+ T cells develop T-cell lymphomas and systemic inflammation that are reminiscent of ATL and HAM/TSP (Satou et al., 2011).

Although HTLV-2 is not causally linked to leukemia or lymphoma, it has been associated with lymphocytosis in infected patients (Bartman et al., 2008). This is consistent with the observation that $\mathrm{APH}-2$ is detected in most PBMCs of HTLV-2-infected patients (Halin et al., 2009) and that its expression is well correlated to proviral DNA load (Douceron et al., 2012). Interestingly, it was observed that the APH-2 mRNA, similarly to HBZ, accumulates in the nucleus (Bender et al., 2012). Barbeau et al. (2013) have recently proposed a model to explain the different effects of HBZ and APH-2 on T-cell proliferation. Both HBZ and of APH-2 can suppress Tax expression, thus favoring evasion of the immune response. In addition, HBZ can stimulate its own expression, inhibit Tax-1-dependent viral expression and induce T-cell proliferation, which can lead to ATL. APH-2 is unable to induce cell proliferation and only partially down-regulates Tax-2 expression.

Although dispensable for the HTLV-1 infection and immortalization of $\mathrm{T}$ lymphocytes in vitro, studies conducted on a rabbit animal model suggest that HBZ enhances HTLV-1infectivity and persistence in vivo (Arnold et al., 2006). Furthermore, HBZ transgenic mice develop systemic inflammation and a CD4+ T-cell neoplasm that is reminiscent of ATL (Satou et al., 2011). Interestingly, in contrast to HBZ, HTLV-2 APH-2 appears to be dispensable for viral infection and persistence in a rabbit animal model (Yin et al., 2012), suggesting a functional divergence of the in vivo function of the HTLV-1 and HTLV-2 antisense proteins.

\section{TROPISM AND CLONALITY}

The preferential cellular tropism of HTLV-1 for CD4+ T cells and of HTLV-2 for CD8+ T cells is still not clearly understood. It appears that the two viruses make different use of the heparan sulfate proteoglycans to enter T cells (Jones et al., 2006), although recent evidence obtained in vivo rabbit model indicates that the apparent tropism for CD4+ or CD8+ cells mainly reflects preferential clonal expansion of infected cells (Kannian et al., 2012). Both HTLV-1 and HTLV-2 are capable of inducing clonal expansion of infected cells in vivo (Wattel et al., 1995; Cimarelli et al., 1996). A detailed analysis in asymptomatic carriers, TSP/HAM and ATLL patients revealed that the genomic integration site and transcriptional orientation of the provirus are important factors for determining clonal abundance in vivo (Gillet et al., 2011).

A very recent study demonstrated that, contrary to previous hypotheses, HTLV-2-infected individuals have a small number of highly expanded CD8+ T-cell clones, suggesting that HTLV-2 may be subjected to a more strict clonal selection than HTLV-1 in healthy carriers. These data suggest that selective clonal proliferation is more directly responsible for determining the viral burden of HTLV-2 than it does for HTLV-1 (Melamed et al., 2014). In contrast to observations made for HTLV-1, the environment surrounding the integration sites does not seem to have a substantial impact on the expansion of HTLV-2-infected clones (Melamed et al., 2014).

The presence of few very abundant HTLV-2-infected clones is apparently reminiscent of the profile found in ATLL patients. However, the fact that HTLV-2 is not causally linked to a T-cell malignancy suggests that clonal abundance and heterogeneity may not per se constitute a determinant of malignant transformation and clinical outcome of HTLV infection (Melamed et al., 2014).

\section{CONCLUSIONS}

From the comparative analysis on the functional properties of HTLV-1 and HTLV-2 reported above, the following major differences can be outlined: (i) HTLV-2 is characterized by a more abundant expression of gene products that may favor viral latency (i.e., p28 and tRex); (ii) Tax-1 presents a PDZ binding motif, which is absent from Tax-2 and allows interaction with host factors regulating the cell cycle and proliferation; in addition, Tax-2 is unable to activate the non-canonical NF- $\kappa \mathrm{B}$ pathway; (iii) Cis-acting inhibitory elements acting at the level of RNA stability are present within HTLV-1 whereas they have not been described in HTLV-2; (iv) while the truncated forms of Rex-2 were shown to inhibit Rex function, the HTLV-1 homologue p21Rex might lack this activity; (v) HTLV-1 expresses p13 and p8, which have not been described in HTLV-2; (vi) HTLV-2 expresses p11, which does not seem to have a homologue in HTLV-1; (vii) unlike APH-2, HBZ presents a basic zipper domain, as well a transcriptional activation domain, which mediate its capacity to enhance its own expression and deregulate several cellular pathways; (viii) HTLV-2 shows in vivo tropism for CD8+ T cells and induces expansion of a relatively small number of highly abundant clones.

In spite of the evidence accumulated so far on the similarities and differences between HTLV-1 and HTLV-2, it is not yet clear why only HTLV-1 causes a T-cell malignancy. While Tax-1 and HBZ induce T-cell lymphomas when expressed as transgenes in animal models, the in vivo transforming activities of Tax-2 and APH-2 have not been investigated. Aside from the NF- $\kappa \mathrm{B}$ pathway, not much information is available regarding the interactions of Tax-2 with cellular pathways known to be engaged by Tax-1. The fact that HTLV-2, contrary to HTLV-1, is characterized by an oligoclonal proliferative distribution in asymptomatic hosts clearly indicates that the etiology of malignant transformation by HTLV-1 cannot be uniquely attributed to this phenomenon.

\section{ACKNOWLEDGMENTS}

The authors thank Luigi Chieco-Bianchi and Donna D'Agostino for discussions. Research on the HTLVs performed by Vincenzo Ciminale and Maria G. Romanelli was supported by grants from the Associazione Italiana per la Ricerca sul Cancro 
(AIRC) - Cariverona and the Universities of Padova and Verona.

\section{REFERENCES}

Albrecht, B., D’Souza, C. D., Ding, W., Tridandapani, S., Coggeshall, K. M., and Lairmore, M. D. (2002). Activation of nuclear factor of activated T cells by human T-lymphotropic virus type 1 accessory protein p12(I). J. Virol. 76, 3493-3501. doi: 10.1128/JVI.76.7.3493-3501.2002

Andresen, V., Pise-Masison, C. A., Sinha-Datta, U., Bellon, M., Valeri, V., Washington Parks, R., et al. (2011). Suppression of HTLV-1 replication by Tax-mediated rerouting of the p13 viral protein to nuclear speckles. Blood 118, 1549-1559. doi: 10.1182/blood-2010-06-293340

Araujo, A., and Hall, W. W. (2004). Human T-lymphotropic virus type II and neurological disease. Ann. Neurol 56, 10-19. doi: 10.1002/ ana.20126

Arnold, J., Yamamoto, B., Li, M., Phipps, A. J., Younis, I., Lairmore, M. D., et al (2006). Enhancement of infectivity and persistence in vivo by HBZ, a natural antisense coded protein of HTLV-1. Blood 15, 107. doi: 10.1182/blood-2005-114551

Avesani, F., Romanelli, M. G., Turci, M., Di Gennaro, G., Sampaio, C., Bidoia, C., et al. (2010). Association of HTLV Tax proteins with TAK1-binding protein 2 and RelA in calreticulin-containing cytoplasmic structures participates in Tax-mediated NF-кB activation. Virology 408, 39-48. doi: 10.1016/j.virol.2010. 08.023

Bai, X. T., Baydoun, H. H., and Nicot, C. (2010). HTLV-I p30: a versatile protein modulating virus replication and pathogenesis. Mol. Aspects Med. 31, 344-349. doi: 10.1016/j.mam.2010.05.004

Bai, X. T., Sinha-Datta, U., Ko, N. L., Bellon, M., and Nicot, C. (2012). Nuclear export and expression of human T-cell leukemia virus type 1 tax/rex mRNA are RxRE/Rex dependent. J. Virol. 86, 4559-4565. doi: 10.1128/JVI.06361-11

Ballaun, C., Farrington, G. K., Dobrovnik, M., Rusche, J., Hauber, J., and Bohnlein, E. (1991). Functional analysis of human T-cell leukemia virus type I rex-response element: direct RNA binding of Rex protein correlates with in vivo activity. $J$. Virol. 65, 4408-4413.

Barbeau, B., Peloponese, J. M., and Mesnard, J. M. (2013). Functional comparison of antisense proteins of HTLV-1 and HTLV-2 in viral pathogenesis. Front. Microbiol. 4:226. doi: $10.3389 /$ fmicb. 2013.00226

Bartman, M. T., Kaidarova, Z., Hirschkorn, D., Sacher, R. A., Fridey, J., Garratty, G., et al. (2008). Long-term increases in lymphocytes and platelets in human Tlymphotropic virus type II infection. Blood 112, 3995-4002. doi: 10.1182/blood2008-05-155960

Bender, C., Rende, F., Cotena, A., Righi, P., Ronzi, P., Cavallari, I. etal. (2012). Temporal regulation of HTLV-2 expression in infected cell lines and patients: evidence for distinct expression kinetics with nuclear accumulation of APH-2 mRNA. Retrovirology 9, 74. doi: 10.1186/17424690-9-74

Biswas, H. H., Kaidarova, Z., Garratty, G., Gibble, J. W., Newman, B. H., Smith J. W., et al. (2010). Increased all-cause and cancer mortality in HTLV-II infection. J. Acquir. Immune. Defic. Syndr. 54, 290-296. doi: 10.1097/QAI.0b013e31 $81 \mathrm{cc} 5481$

Black, A. C., Chen, I. S., Arrigo, S., Ruland, C. T., Allogiamento, T., Chin, E., et al. (1991). Regulation of HTLV-II gene expression by Rex involves positive and negative cis-acting elements in the $5^{\prime}$ long terminal repeat. Virology 181, 433-444. doi: 10.1016/0042-6822(91)90875-C

Bogerd, H. P., Fridell, R. A., Madore, S., and Cullen, B. R. (1995). Identification of a novel cellular cofactor for the Rev/Rex class of retroviral regulatory proteins. Cel 82, 485-494. doi: 10.1016/0092-8674(95)90437-9

Bogerd, H. P., Huckaby, G. L., Ahmed, Y. F., Hanly, S. M., and Greene, W. C. (1991). The type I human T-cell leukemia virus (HTLV-I) Rex trans-activator binds directly to the HTLV-I Rex and the type 1 human immunodeficiency virus Rev RNA response elements. Proc. Natl Acad. Sci. U.S.A. 88, 5704-5708. doi 10.1073/pnas.88.13.5704

Cavallari, I., Rende F., Bender C., Romanelli, M. G., D’Agostino, D. M., and Ciminale V. (2013). Fine tuning of the temporal expression of HTLV-1 and HTLV-2. Front. Microbiol. 4:235. doi: 10.3389/fmicb.2013.00235

Cheng, H., Ren, T., and Sun, S. C. (2012). New insight into the oncogenic mechanism of the retroviral oncoprotein Tax. Protein Cell 3, 581-589. doi: 10.1007/s13238012-2047-0
Cimarelli, A., Duclos, C. A., Gessain, A., Casoli, C., and Bertazzoni, U. (1996). Clonal expansion of human T-cell leukemia virus type II in patients with high proviral load. Virology 223, 362-364. doi: 10.1006/viro.1996.0487

Ciminale, V., D’Agostino, D. M., Zotti, L., Franchini, G., Felber, B. K., and ChiecoBianchi, L. (1995). Expression and characterization of proteins produced by mRNAs spliced into the $\mathrm{X}$ region of the human T-cell leukemia/lymphotropic virus type II. Virology 209, 445-456. doi: 10.1006/viro.1995.1277

Ciminale, V., Pavlakis, G. N., Derse, D., Cunningham, C. P., and Felber, B. K. (1992). Complex splicing in the human T-cell leukemia virus (HTLV) family of retroviruses: novel mRNAs and proteins produced by HTLV type I. J. Virol. 66, 1737-1745.

Ciminale, V., Zotti, L., D’Agostino, D. M., and Chieco-Bianchi, L. (1997). Inhibition of human T-cell leukemia virus type 2 Rex function by truncated forms of Rex encoded in alternatively spliced mRNAs. J. Virol. 71, 2810-2818.

Ciminale, V., Zotti, L., D’Agostino, D. M., Ferro, T., Casareto, L., Franchini, G., et al. (1999). Mitochondrial targeting of the p13II protein coded by the X-II ORF of human T-cell leukemia/lymphotropic virus type I (HTLV-I). Oncogene 18, 4505-4514. doi: 10.1038/sj.onc.1203047

Clerc, I., Polakowski, N., Andre-Arpin, C., Cook, P., Barbeau, B., Mesnard, J. M., et al. (2008). An interaction between the human $\mathrm{T}$ cell leukemia virus type 1 basic leucine zipper factor (HBZ) and the KIX domain of p300/CBP contributes to the down-regulation of tax-dependent viral transcription by HBZ. J. Biol. Chem. 283, 23903-23913. doi: 10.1074/jbc.M803116200

Corradin, A., Di Camillo, B., Ciminale, V., Toffolo, G., and Cobelli, C. (2011). Sensitivity analysis of retrovirus HTLV-1 transactivation. J. Comput. Biol. 18, 183-193. doi: 10.1089/cmb.2010.0219

D’Agostino, D. M., Bernardi, P., Chieco-Bianchi, L., and Ciminale, V. (2005). Mitochondria as functional targets of proteins coded by human tumor viruses. $A d v$. Cancer Res. 94, 87-142. doi: 10.1016/S0065-230X(05)94003-7

D’Agostino, D. M., Ciminale, V., Zotti, L., Rosato, A., and Chieco-Bianchi, L. (1997). The human T-cell lymphotropic virus type 1 Tof protein contains a bipartite nuclear localization signal that is able to functionally replace the amino-terminal domain of Rex. J. Virol. 71, 75-83.

D’Agostino, D. M., Ranzato, L., Arrigoni, G., Cavallari, I., Belleudi, F., Torrisi, M. R., et al. (2002). Mitochondrial alterations induced by the $\mathrm{p} 13^{I I}$ protein of human T-cell leukemia virus type 1. Critical role of arginine residues. J. Biol. Chem. 277 34424-34433. doi: 10.1074/jbc.M203023200

Datta, A., Sinha-Datta, U., Dhillon, N. K., Buch, S., and Nicot, C. (2006). The HTLV-I p30 interferes with TLR4 signaling and modulates the release of proand anti-inflammatory cytokines from human macrophages. J. Biol. Chem. 281, 23414-23424. doi: 10.1074/jbc.M600684200

Ding, W., Albrecht, B., Kelley, R. E., Muthusamy, N., Kim, S. J., Altschuld, R. A., et al. (2002). Human T-cell lymphotropic virus type 1 p12(I) expression increases cytoplasmic calcium to enhance the activation of nuclear factor of activated $\mathrm{T}$ cells. J. Virol. 76, 10374-10382. doi: 10.1128/JVI.76.20.10374-10382.2002

Ding, W., Albrecht, B., Luo, R., Zhang, W., Stanley, J. R., Newbound, G. C., et al. (2001). Endoplasmic reticulum and cis-Golgi localization of human Tlymphotropic virus type $1 \mathrm{p} 12(\mathrm{I})$ : association with calreticulin and calnexin. $J$. Virol. 75, 7672-7682. doi: 10.1128/JVI.75.16.7672-7682.2001

Douceron, E., Kaidarova, Z., Miyazato, P., Matsuoka, M., Murphy, E. L., and Mahieux, R. (2012). HTLV-2 APH-2 expression is correlated with proviral load but APH-2 does not promote lymphocytosis. J. Infect. Dis. 205, 82-86. doi: 10.1093/infdis/jir708

Gaudray, G., Gachon, F., Basbous, J., Biard-Piechaczyk, M., Devaux, C., and Mesnard, J. M. (2002). The complementary strand of HTLV-1 RNA genome encodes bZIP transcription factor that down-regulates the viral trasncription. J. Virol. 76, 12813-12822. doi: 10.1128/JVI.76.24.12813-12822.2002

Gazon, H., Lemasson, I., Polakowski, N., Cesaire, R., Matsuoka, M., Barbeau, B., et al. (2012). Human T-cell leukemia virus type 1 (HTLV-1) bZIP factor requires cellular transcription factor JunD to upregulate HTLV-1 antisense transcription from the $3^{\prime}$ long terminal repeat. J. Virol. 86, 9070-9078. doi: 10.1128/JVI. 00661-12

Gessain, A., and Cassar, O. (2012). Epidemiological aspects and world distribution of HTLV-1 infection. Front. Microbiol. 3:388. doi: 10.3389/fmicb.2012. 00388

Gessain, A., and Mahieux, R. (2012). Tropical spastic paraparesis and HTLV-1 associated myelopathy: clinical, epidemiological, virological and therapeutic aspects. Rev. Neurol. (Paris) 168, 257-269. doi: 10.1016/j.neurol.2011.12.006 
Gessain, A., Rua, R., Betsem, E., Turpin, J., and Mahieux, R. (2013). HTLV-3/4 and simian foamy retroviruses in humans: discovery, epidemiology, crossspecies transmission and molecular virology. Virology 435, 187-199. doi: 10.1016/j.virol.2012.09.035

Gillet, N. A., Malani, N., Melamed, A., Gormley, N., Carter, R., Bentley, D., et al (2011). The host genomic environment of the provirus determines the abundance of HTLV-1-infected T-cell clones. Blood 117, 3113-3122. doi: 10.1182/blood2010-10-312926

Grassmann, R., Berchtold, S., Aepinus, C., Ballaun, C., Boehnlein, E., and Fleckenstein, B. (1991). In vitro binding of human T-cell leukemia virus rex proteins to the rex-response element of viral transcripts. J. Virol. 65, 3721-3727.

Halin, M., Douceron, E., Clerc, I., Journo, C., Ko, N. L., Landry, S., et al. (2009). Human T-cell leukemia virus type 2 produces a spliced antisense transcript encoding a protein that lacks a classic bZIP domain but still inhibits Tax2-mediated transcription. Blood 114, 2427-2438. doi: 10.1182/blood-2008-09-179879

Hasegawa, H., Sawa, H., Lewis, M. J., Orba, Y., Sheehy, N., Yamamoto, Y., et al. (2006). Thymus-derived leukemia-lymphoma in mice transgenic for the Tax gene of human T-lymphotropic virus type I. Nat. Med. 12, 466-472. doi:10.1038/nm1389

Heger, P., Rosorius, O., Hauber, J., and Stauber, R. H. (1999). Titration of cellular export factors, but not heteromultimerization, is the molecular mechanism of trans-dominant HTLV-1 rex mutants. Oncogene 18, 4080-4090. doi: 10.1038/sj.onc. 1202762

Higuchi, M., and Fujii, M. (2009). Distinct functions of HTLV-1 Tax1 from HTLV2 Tax 2 contribute key roles to viral pathogenesis. Retrovirology 6, 117. doi: 10.1186/1742-4690-6-117

Hiraragi, H., Kim, S. J., Phipps, A. J., Silic-Benussi, M., Ciminale, V., Ratner, L., et al. (2006). Human T-lymphotropic virus type 1 mitochondrion-localizing protein p13(II) is required for viral infectivity in vivo. J. Virol. 80, 3469-3476. doi: 10.1128/JVI.80.7.3469-3476.2006

Hiraragi, H., Michael, B., Nair, A., Silic-Benussi, M., Ciminale, V., and Lairmore, M. (2005). Human T-lymphotropic virus type 1 mitochondrion-localizing protein p13II sensitizes Jurkat T cells to Ras-mediated apoptosis. J. Virol. 79, 9449-9457. doi: 10.1128/JVI.79.15.9449-9457.2005

Hivin, P., Arpin-Andre, C., Clerc, I., Barbeau, B., and Mesnard, J. M. (2006). A modified version of a Fos-associated cluster in HBZ affects Jun transcriptional potency. Nucleic Acids Res. 34, 2761-2772. doi: 10.1093/nar/gkl375

Hivin, P., Frédéric, M., Arpin-Andrè, C., Basbous, J., Gay, B., Thébault, S., et al. (2005). Nuclear localization of HTLV-1 bZIP factor (HBZ) is mediated by three distinct motifs. J. Cell. Sci. 118, 1355-1362. doi: 10.1242/jcs.01727

Huang, J., Ren, T., Guan, H., Jiang, Y., and Cheng, H. (2009). HTLV-1 Tax is a critical lipid raft modulator that hijacks IкB kinases to the microdomains for persistent activation of NF-кB. J. Biol. Chem. 284, 6208-6217. doi: 10.1074/jbc.M806 390200

Ijichi, S., Ramundo, M. B., Takahashi, H., and Hall, W. W. (1992). In vivo cellular tropism of human T cell leukemia virus type II (HTLV-II). J. Exp. Med. 176, 293-296. doi: 10.1084/jem.176.1.293

Imai, M., Higuchi, M., Kawamura, H., Yoshita, M., Takahashi, M., Oie, M., et al. (2013). Human T cell leukemia virus type 2 (HTLV-2) Tax2 has a dominant activity over HTLV-1 Tax1 to immortalize human CD4+ T cells. Virus Genes 46, 39-46. doi: 10.1007/s11262-012-0831-9

Johnson, J. M., Mulloy, J. C., Ciminale, V., Fullen, J., Nicot, C., and Franchini, G. (2000). The MHC class I heavy chain is a common target of the small proteins encoded by the $3^{\prime}$ end of HTLV type 1 and HTLV type 2. AIDS Res. Hum. Retroviruses 16, 1777-1781. doi: 10.1089/08892220 050193308

Johnson, J. M., Nicot, C., Fullen, J., Ciminale, V., Casareto, L., Mulloy, J. C., et al. (2001). Free major histocompatibility complex class I heavy chain is preferentially targeted for degradation by human T-cell leukemia/lymphotropic virus type 1 p12(I) protein. J. Virol. 75, 6086-6094. doi: 10.1128/JVI.75.13.60866094.2001

Jones, K. S., Fugo, K., Petrow-Sadowski, C., Huang, Y., Bertolette, D. C., Lisinski, I., et al. (2006). Human T-cell leukemia virus type 1 HTLV-1 and HTLV-2 use different receptor complexes to enter T cells. J. Virol. 80, 8291-8302. doi: 10.1128/JVI.00389-06

Journo, C., Bonnet, A., Favre-Bonvin, A., Turpin, J., Vinera, J., Cote, E., et al. (2013). Human $\mathrm{T}$ cell leukemia virus type 2 tax-mediated NF- $\kappa$ B activation involves a mechanism independent of Tax conjugation to ubiquitin and SUMO. J. Virol. 87, 1123-1136. doi: 10.1128/JVI.01792-12
Kannian, P., Yin, H., Doueiri, R., Lairmore, M. D., Fernandez, S., and Green, P. L. (2012). Distinct transformation tropism exhibited by human T lymphotropic virus type 1 (HTLV-1) and HTLV-2 is the result of postinfection T cell clonal expansion. J. Virol. 86, 3757-3766. doi: 10.1128/JVI.06900-11

Kim, F. J., Beeche, A. A., Hunter, J. J., Chin, D. J., and Hope, T. J. (1996). Characterization of the nuclear export signal of human T-cell lymphotropic virus type 1 Rex reveals that nuclear export is mediated by position-variable hydrophobic interactions. Mol. Cell. Biol. 16, 5147-5155.

Kim, S. J., Ding, W., Albrecht, B., Green, P. L., and Lairmore, M. D. (2003). A conserved calcineurin-binding motif in human T lymphotropic virus type 1 p12I functions to modulate nuclear factor of activated T cell activation. J. Biol. Chem. 278, 15550-15557. doi: 10.1074/jbc.M210210200

King, J. A., Bridger, J. M., Lochelt, M., Lichter, P., Schulz, T. F., Schirrmacher, V., et al. (1998). Nucleocytoplasmic transport of HTLV-1 RNA is regulated by two independent LTR encoded nuclear retention elements. Oncogene 16, 3309-3316. doi: 10.1038/sj.onc.1201884

Koralnik, I. J., Gessain, A., Klotman, M. E., Lo Monico, A., Berneman, Z. N., and Franchini, G. (1992). Protein isoforms encoded by the pX region of human T-cell leukemia/lymphotropic virus type I. Proc. Natl. Acad. Sci. U.S.A. 89, 8813-8817. doi: 10.1073/pnas.89.18.8813

Lodewick, J., Sampaio, C., Boxus, M., Rinaldi, A. S., Coulonval, K., Willems, L., et al. (2013). Acetylation at lysine 346 controls the transforming activity of the HTLV-1 Tax oncoprotein in the Rat-1 fibroblast model. Retrovirology 10, 75. doi: 10.1186/1742-4690-10-75

Marban, C., McCabe, A., Bukong, T. N., Hall, W. W., and Sheehy, N. (2012). Interplay between the HTLV-2 Tax and APH-2 proteins in the regulation of the AP-1 pathway. Retrovirology 9, 98. doi: 10.1186/1742-4690-9-98

Melamed, A., Witkover, A. D., Laydon, D. J., Brown, R., Ladell, K., Miners, K., et al. (2014). Clonality of HTLV-2 in natural infection. PLoS Pathog. 10:e1004006. doi: 10.1371/journal.ppat.1004006

Michael, B., Nair, A. M., Hiraragi, H., Shen, L., Feuer, G., Boris-Lawrie, K., et al. (2004). Human T lymphotropic virus type-1 p30II alters cellular gene expression to selectively enhance signaling pathways that activate $\mathrm{T}$ lymphocytes. Retrovirology 1, 39. doi: 10.1186/1742-4690-1-39

Mulloy, J. C., Crownley, R. W., Fullen, J., Leonard, W. J., and Franchini, G. (1996). The human T-cell leukemia/lymphotropic virus type 1 p12I proteins bind the interleukin-2 receptor $\beta$ and $\gamma_{c}$ chains and affects their expression on the cell surface. J. Virol. 70, 3599-3605.

Narayan, M., Younis, I., D’Agostino, D. M., and Green, P. L. (2003). Functional domain structure of human T-cell leukemia virus type 2 rex. J. Virol. 77, 1282912840. doi: 10.1128/JVI.77.23.12829-12840.2003

Nejmeddine, M., Barnard, A. L., Tanaka, Y., Taylor, G. P., and Bangham, C. R. (2005). Human T-lymphotropic virus, type 1, tax protein triggers microtubule reorientation in the virological synapse. J. Biol. Chem. 280, 29653-29660. doi: 10.1074/jbc.M502639200

Nicot, C., Dundr, M., Johnson, J. M., Fullen, J. R., Alonzo, N., Fukumoto, R., et al. (2004). HTLV-1-encoded p30(II) is a post-transcriptional negative regulator of viral replication. Nat. Med., 197-201. doi: 10.1038/nm984

Nicot, C., Mulloy, J. C., Ferrari, M. G., Johnson, J. M., Fu, K., Fukumoto, R., et al. (2001). HTLV-1 p12(I) protein enhances STAT5 activation and decreases the interleukin-2 requirement for proliferation of primary human peripheral blood mononuclear cells. Blood 98, 823-829. doi: 10.1182/blood.V98.3.823

Nosaka, T., Miyazaki, Y., Takamatsu, T., Sano, K., Nakai, M., Fujita, S., et al. (1995). The post-transcriptional regulator Rex of the human T-cell leukemia virus type I is present as nucleolar speckles in infected cells. Exp. Cell Res. 219, 122-129. doi: 10.1006/excr.1995.1212

Nosaka, T., Siomi, H., Adachi, Y., Ishibashi, M., Kubota, S., Maki, M., et al. (1989). Nucleolar targeting signal of human T-cell leukemia virus type I rex-encoded protein is essential for cytoplasmic accumulation of unspliced viral mRNA. Proc. Natl. Acad. Sci. U.S.A. 86, 9798-9802. doi: 10.1073/pnas.86.24.9798

Ohta, M., Nyunoya, H., Tanaka, H., Okamoto, T., Akagi, T., and Shimotohno, K. (1988). Identification of a cis-regulatory element involved in accumulation of human T-cell leukemia virus type II genomic mRNA. J. Virol. 62, 4445-4451.

Palmeri, D., and Malim, M. H. (1996). The human T-cell leukemia virus type 1 posttranscriptional trans-activator Rex contains a nuclear export signal. J. Virol. 70, 6442-6445.

Pique, C., and Jones, K. S. (2012). Pathways of cell-cell transmission of HTLV-1. Front. Microbiol. 3:378. doi: 10.3389/fmicb.2012.00378 
Ren, T., Takahashi, Y., Liu, X., Loughran, T. P., Sun, S. C., Wang, H. G., et al. (2013). HTLV-1 Tax deregulates autophagy by recruiting autophagic molecules into lipid raft microdomains. Oncogene 1-12. doi: 10.1038/onc.2013.552

Rende, F., Cavallari, I., Corradin, A., Silic-Benussi, M., Toulza, F., Toffolo, G. M., et al. (2011). Kinetics and intracellular compartmentalization of HTLV-1 gene expression: nuclear retention of HBZ mRNA. Blood 117, 4855-4859. doi 10.1182/blood-2010-11-316463

Romanelli, M. G., Diani, E., Bergamo, E., Casoli, C., Ciminale, V., Bex, F., et al. (2013). Highlights on distinctive structural and functional properties of HTLV Tax proteins. Front. Microbiol. 4:271. doi: 10.3389/fmicb.2013.00271

Roucoux, D. F., and Murphy, E. L. (2004). The epidemiology and disease outcomes of human T-lymphotropic virus type II. AIDS Rev. 6, 144-154.

Ruddle, N. H., Li, C. B., Horne, W. C., Santiago, P., Troiano, N., Jay, G., etal. (1993). Mice transgenic for HTLV-I LTR-tax exhibit tax expression in bone, skeletal alterations, and high bone turnover. Virology 197, 196-204. doi: 10.1006/viro.1993.1580

Saiga, A., Orita, S., Minoura-Tada, N., Maeda, M., Aono, Y., Asakawa, M., et al (1997). cis-Acting inhibitory elements within the pol-env region of human Tcell leukemia virus type 1 possibly involved in viral persistence. J. Virol. 71 , 4485-4494.

Satou, Y., Yasunaga, J., Yoshida, M., and Matsuoka, M. (2006). HTLV-I basic leucine zipper factor gene mRNA supports proliferation of adult T cell leukemia cells. Proc. Natl. Acad. Sci. U.S.A. 103, 720-725. doi: 10.1073/pnas.05076 31103

Satou, Y., Yasunaga, J., Zhao, T., Yoshida, M., Miyazato, P., Takai, K., et al. (2011). HTLV-1 bZIP factor induces T-cell lymphoma and systemic inflammation in vivo. PLoS Pathog. 7:e1001274. doi: 10.1371/journal.ppat.1001274

Seiki, M., Hattori, S., Hirayama, Y., and Yoshida, M. (1983). Human adult T-cell leukemia virus: complete nucleotide sequence of the provirus genome integrated in leukemia cell DNA. Proc. Natl. Acad. Sci. U.S.A. 80, 3618-3622. doi: $10.1073 /$ pnas.80.12.3618

Seiki, M., Hikikoshi, A., and Yoshida, M. (1990). The U5 sequence is a cis-acting repressive element for genomic RNA expression of human $\mathrm{T}$ cell leukemia virus type I. Virology 176, 81-86. doi: 10.1016/0042-6822(90) 90232-G

Semmes O. J., Majone F., Cantemir C., Turchetto L., Hjelle B., and Jeang, K.-T. (1996). HTLV-I and HTLV-II Tax: Differences in induction of micronuclei in cells and transcriptional activation of viral LTRs. Virology 217, 373-379. doi: 10.1006/viro.1996.0126

Shoji, T., Higuchi, M., Kondo, R., Takahashi, M., Oie, M., Tanaka, Y., et al. (2009). Identification of a novel motif responsible for the distinctive transforming activity of human T-cell leukemia virus (HTLV) type 1 Tax1 protein from HTLV-2 Tax2. Retrovirology 6, 83. doi: 10.1186/1742-4690-6-83

Silic-Benussi, M., Biasiotto, R., Andresen, V., Franchini, G., D’Agostino, D. M., and Ciminale, V. (2010a). HTLV-1 p13, a small protein with a busy agenda. Mol. Aspects Med. 350-358. doi: 10.1016/j.mam.2010. 03.001

Silic-Benussi, M., Cavallari, I., Vajente, N., Vidali, S., Chieco-Bianchi, L., Di Lisa, F., et al. (2010b). Redox regulation of T-cell turnover by the p13 protein of human T-cell leukemia virus type 1: distinct effects in primary versus transformed cells. Blood 116, 54-62. doi: 10.1182/blood-2009-07-235861

Silic-Benussi, M., Cannizzaro, E., Venerando, A., Cavallari, I., Petronilli, V., La Rocca, N., et al. (2009). Modulation of mitochondrial $\mathrm{K}(+)$ permeability and reactive oxygen species production by the p13 protein of human T-cell leukemia virus type 1. Biochim. Biophys. Acta 1787, 947-954. doi: 10.1016/j.bbabio.2009. 02.001

Silic-Benussi, M., Cavallari, I., Zorzan, T., Rossi, E., Hiraragi, H., Rosato, A., et al (2004). Suppression of tumor growth and cell proliferation by p13II, a mitochondrial protein of human T cell leukemia virus type 1. Proc. Natl. Acad. Sci. U.S.A. 101, 6629-6634. doi: 10.1073/pnas.0305502101

Silverman, L. R., Phipps, A. J., Montgomery, A., Ratner, L., and Lairmore, M. D. (2004). Human T-cell lymphotropic virus type 1 open reading frame II-encoded p30II is required for in vivo replication: evidence of in vivo reversion. J. Virol. 78, 3837-3845. doi: 10.1128/JVI.78.8.3837-3845.2004

Sinha-Datta, U., Datta, A., Ghorbel, S., Dodon, M. D., and Nicot, C. (2007). Human T-cell lymphotrophic virus type I rex and p30 interactions govern the switch between virus latency and replication. J. Biol. Chem. 282, 14608-14615. doi: 10.1074/jbc.M611219200
Siomi, H., Shida, H., Nam, S. H., Nosaka, T., Maki, M., and Hatanaka, M. (1988). Sequence requirements for nucleolar localization of human $\mathrm{T}$ cell leukemia virus type I pX protein, which regulates viral RNA processing. Cell 55, 197-209. doi: 10.1016/0092-8674(88)90043-8

Suzuki, T., Ohsugi, Y., Uchida-Toita, M., Akiyama, T., and Yoshida, M. (1999). Tax oncoprotein of HTLV-1 binds to the human homologue of Drosophila discs large tumor suppressor protein, hDLG, and perturbs its function in cell growth control. Oncogene 18, 5967-5972. doi: 10.1038/sj.onc. 1203008

Tanaka, A., Takahashi, C., Yamaoka, S., Nosaka, T., Maki, M., and Hatanaka, M. (1990). Oncogenic transformation by the tax gene of human T-cell leukemia virus type I in vitro. Proc. Natl. Acad. Sci. U.S.A. 87, 1071-1075. doi: 10.1073/pnas.87.3.1071

Taylor, J. M., Ghorbel, S., and Nicot, C. (2009). Genome wide analysis of human genes transcriptionally and post-transcriptionally regulated by the HTLV-I protein p30. BMC Genomics 10:311. doi: 10.1186/1471-216410-311

Turci, M., Lodewick, J., Di Gennaro, G., Rinaldi, A. S., Marin, O., Diani, E., etal. (2012). Ubiquitination and sumoylation of the HTLV2 Tax-2B protein regulate its NF-кB activity: a comparative study with the HTLV-1 Tax-1 protein. Retrovirology 9, 102. doi: 10.1186/1742-46909-102

Turci, M., Lodewick, J., Righi, P., Polania, A., Romanelli, M. G., Bex, F., et al. (2009). HTLV-2B Tax oncoprotein is modified by ubiquitination and sumoylation and displays intracellular localization similar to its homologue HTLV-1 Tax. Virology 386, 6-11. doi: 10.1016/j.virol.2009.01.003

Turci, M., Romanelli, M. G., Lorenzi, P., Righi, P., and Bertazzoni, U. (2006). Localization of human T-cell lymphotropic virus type II Tax protein is dependent upon a nuclear localization determinant in the N-terminal region. Gene 365, 119-124. doi: 10.1016/j.gene.2005.09.043

Unge, T., Solomin, L., Mellini, M., Derse, D., Felber, B. K., and Pavlakis, G. N. (1991). The Rex regulatory protein of human T-cell lymphotropic virus type I binds specifically to its target site within the viral RNA. Proc. Natl. Acad. Sci. U.S.A. 88, 7145-7149. doi: 10.1073/pnas.88.16.7145

Valeri, V. W., Hryniewicz, A., Andresen, V., Jones, K., Fenizia, C., Bialuk, I., et al. (2010). Requirement of the human T-cell leukemia virus p12 and p30 products for infectivity of human dendritic cells and macaques but not rabbits. Blood 116, 3809-3817. doi: 10.1182/blood-2010-05-284141

Van Prooyen, N., Andresen, V., Gold, H., Bialuk, I., Pise-Masison, C., and Franchini, G. (2010a). Hijacking the T-cell communication network by the human T-cell leukemia/lymphoma virus type 1 (HTLV-1) p12 and p8 proteins. Mol. Aspects Med. 31, 333-343. doi: 10.1016/j.mam.2010. 07.001

Van Prooyen, N., Gold, H., Andresen, V., Schwartz, O., Jones, K., Ruscetti, F., et al. (2010b). Human T-cell leukemia virus type 1 p8 protein increases cellular conduits and virus transmission. Proc. Natl. Acad. Sci. U.S.A. 107, 20738-20743. doi: 10.1073/pnas.1009635107

Wattel, E., Vartanian, J. P., Pannetier, C., and Wain-Hobson, S. (1995). Clonal expansion of human T-cell leukemia virus type I-infected cells in asymptomatic and symptomatic carriers without malignancy. J. Virol. 69, 2863-2868.

Weichselbraun, I., Farrington, G. K., Rusche, J. R., Bohnlein, E., and Hauber, J. (1992). Definition of the human immunodeficiency virus type 1 Rev and human T-cell leukemia virus type I Rex protein activation domain by functional exchange. J. Virol. 66, 2583-2587.

Xiao, G. (2012). NF-кB activation: Tax sumoylation is out, but what about Tax ubiquitination? Retrovirology 9, 78. doi: 10.1186/17424690-9-78

Yamamoto, B., Li, M., Kesic, M., Younis, I., Lairmore, M. D., and Green, P. L. (2008). Human T-cell leukemia virus type 2 post-transcriptional control protein p28 is required for viral infectivity and persistence in vivo. Retrovirology 5, 38. doi: 10.1186/1742-4690-5-38

Ye, J., Silverman, L., Lairmore, M. D., and Green, P. L. (2003). HTLV-1 Rex is required for viral spread and persistence in vivo but is dispensable for cellular immortalization in vitro. Blood 102, 3963-3969. doi: 10.1182/blood-2003-051490

Yin, H., Kannian, P., Dissinger, N., Haines, R., Niewiesk, S., and Green, P. L. (2012). Human T-cell leukemia virus type 2 antisense viral protein 2 is dispensable for 
in vitro immortalization but functions to repress early virus replication in vivo. J. Virol. 86, 8412-8421. doi: 10.1128/JVI.00717-12

Younis, I., Khair, L., Dundr, M., Lairmore, M. D., Franchini, G., and Green, P. L. (2004). Repression of human T-cell leukemia virus type 1 and type 2 replication by a viral mRNA-encoded posttranscriptional regulator. J. Virol. 78, 11077-11083. doi: 10.1128/JVI.78.20.11077-11083 .2004

Zane, L., and Jeang, K. T. (2012). The importance of ubiquitination and sumoylation on the transforming activity of HTLV Tax-1 and Tax-2. Retrovirology 9, 103. doi: 10.1186/1742-4690-9-103

Zella, D., Mori, L., Sala, M., Ferrante, P., Casoli, C., Magnani, G., et al. (1990). HTLVII infection in Italian drug abusers. Lancet 336, 575-576. doi: 10.1016/01406736(90)92140-D

Zhang, W., Nisbet, J. W., Albrecht, B., Ding, W., Kashanchi, F., Bartoe, J. T., et al. (2001). Human T-lymphotropic virus type 1 p30(II) regulates gene transcription by binding CREB binding protein/p300. J. Virol. 75, 9885-9895. doi: 10.1128/JVI.75.20.9885-9895.2001

Zhang, W., Nisbet, J. W., Bartoe, J. T., Ding, W., and Lairmore, M. D. (2000). Human T-lymphotropic virus type 1 p30(II) functions as a transcription factor and differentially modulates CREB-responsive promoters. J. Virol. 74, 11270-11277. doi: 10.1128/JVI.74.23.1127011277.2000

Conflict of Interest Statement: The authors declare that the research was conducted in the absence of any commercial or financial relationships that could be construed as a potential conflict of interest.

Received: 26 May 2014; accepted: 15 July 2014; published online: 29 July 2014. Citation: Ciminale V, Rende F, Bertazzoni U and Romanelli MG (2014) HTLV-1 and HTLV-2: highly similar viruses with distinct oncogenic properties. Front. Microbiol. 5:398. doi: 10.3389/fmicb.2014.00398

This article was submitted to Virology, a section of the journal Frontiers in Microbiology. Copyright (c) 2014 Ciminale, Rende, Bertazzoni and Romanelli. This is an openaccess article distributed under the terms of the Creative Commons Attribution License (CC BY). The use, distribution or reproduction in other forums is permitted, provided the original author(s) or licensor are credited and that the original publication in this journal is cited, in accordance with accepted academic practice. No use, distribution or reproduction is permitted which does not comply with these terms. 